\title{
OPTIMASI HIDROLIKA SUMUR "SH" LAPANGAN "U” KALIMANTAN TIMUR DENGAN METODE BIT HYDROULIC HORSE POWER
}

\author{
Sri Haryono \\ Program Studi Teknik Perminyakan, Fakultas Teknik, Universitas Proklamasi 45 \\ Corresponding author, email : aafaga@gmail.com
}

\begin{abstract}
Abstrak
Lapangan "U" ditempatkan di Cekungan Tarakan, yang merupakan salah satu daerah cekungan hidrokarbon Kalimantan Timur. Formasi yang ditembus oleh mata bor terdiri dari batupasir, batulanau, batulempung dan batubara. Oleh karena itu, kita perlu mengatur ulang sistem lumpur pengeboran terutama pada sistem hidrolik lumpur pengeboran. Penelitian ini bertujuan untuk mengoptimalkan sistem hidrolik dalam proses pengeboran untuk sumur "SH" Lapangan "U" menggunakan metode Bit Hydraulic Horse Power (BHHP). Hasil dari metode ini adalah untuk menentukan laju alir fluida BHHP yang optimal, daya tembus, ukuran nozzle, dan membandingkan parameter ini dengan data pengeboran aktual sebelum optimasi (data aktual) sehingga penetrasi proses pembentukan juga optimal. Berdasarkan data aktual dari semua pengeboran sumur ke 13 titik kedalaman harus dioptimalkan terutama dalam sistem pengeboran hidrolik dengan mengubah ukuran area aperture pada nozzle bor dan daya sesuai dengan perhitungan.
\end{abstract}

Kata kunci : Bit Hydraulic Horse Power, Laju Alir, Nozzle

\begin{abstract}
" $U$ " Field placed on the Tarakan Basin, which is one hydrocarbon basins area of East Kalimantan. Formation that penetrated by the drill bit consist of sandstone, siltstone, clay stone and coal. Therefore, we need to rearrange the drilling mud system particularly on drilling mud hydraulics system. This study aims to optimize the hydraulic system in the process of drilling for wells "SH" Fields "U" using bit hydraulic Horse Power (BHHP) method. The output of this method are to determine the optimum BHHP fluid flow rate, penetrating power, nozzle size, and compare these parameters with the actual drill data before optimization (actual data) so that the penetration of the formation process is also optimal. Based on the actual data of all well drilling to 13 depth points must be optimized especially in the hydraulic drilling system by changing the size of the aperture area at the drill nozzle and power according to the calculation using the BHHP method.
\end{abstract}

Keywords : Bit Hydraulic Horse Power, Flow rate, Nozzle

\section{Pendahuluan}

Kegiatan operasional pemboran diharapkan dapat berjalan efisien dan ekonomis. Untuk itu perlu adanya perbaikan sarana yang menunjang, salah satunya adalah dengan mengevalausi sistem hidrolika lumpur dan mengoptimasi sistem tersebut. Tujuan optimasi sistem hidrolika pada pemboran yaitu untuk mendapatkan daya (horsepower) bit hydraulic maksimum, menambah gaya impak jet, meningkatkan efek pembersihan dasar lubang bor, dan mengangkat serbuk bor dari annulus ke permukaan sehingga dapat membantu meningkatkan laju pemboran (Guan et al., 2015)

Pada optimasi hidrolika, lumpur memegang peranan penting dalam operasi pemboran terutama dalam proses pembersihan cutting di dasar sumur dan pengangkatan cutting ke permukaan (Al-Kayiem et al., 2010). Faktor yang mempengaruhi pengangkatan cutting pada sumur diantaranya:(1) kecepatan fluida di annulus sebagai fungsi dari luas area annulus; (2) laju pemompaan yang diberikan; (3) kapasitas untuk menahan fluida yang merupakan fungsi dari rheology lumpur pemboran (densitas lumpur, aliran laminer/turbulen, vis-kositas); (4) laju penembusan (rate of penetration) yang dilakukan;(5) kecepatan pemutaran pipa pemboran (rpm); dan (6) ukuran partikel cutting (Paiaman et al., 2006)

\subsection{Lumpur Pemboran}

Fluida pemboran adalah suatu fluida yang bersirkulasi dalam pemboran putar, yang mempunyai berbagai fungsi yang diperlukan dalam operasi pemboran. Jenis lumpur pemboran yang sesuai dengan karateristik sumur akan mendukung keberhasilan operasi pemboran terutama pada pola aliran serta kecepatan pemboran serta keberhasilan pengangkatan cutting ke permukaan (Coussot et al., 2004) 


\section{OPTIMASI HIDROLIKA SUMUR "SH" LAPANGAN "U" KALIMANTAN TIMUR DENGAN METODE BIT HYDROULIC HORSE POWER}

\subsection{Rheology Lumpur Pemboran}

Rheology yaitu mengetahui tentang perubahan bentuk dan aliran dari suatu jenis fluida. Sifat rheology ini dijelaskan dengan hubungan antara gaya dari fluida terhadap aliran dalam satuan tekanan persatuan luas (shear stress) dengan besarnya laju perubahan kecepatan aliran antar lapisan yang terjadi waktu fluida mengalir dalam satuan kecepatan persatuan panjang (shear rate) (Miguez et al., 2011). Rheology lumpur pemboran meliputi sifat aliran dan jenis fluda pemboran. Sifat aliran meliputi aliran laminer dan aliran turbulen sedangkan jenis fluida pemboran meliputi fluida Newtonian dan non-Newtonian (Kelessidis, et al., 2011). Untuk menentukan aliran tersebut turbulen atau laminer digunakan Reynold Number :

$N_{\mathrm{Re}}=928 \frac{\rho V d}{\mu}$

dimana:

$\rho=$ Density fluida, $\mathrm{lbm} / \mathrm{gal}$

$\mathrm{V}=$ Kecepatan aliran, $\mathrm{ft} / \mathrm{sec}$

$\mathrm{d}=$ Diameter pipa, in

$\mu=$ Viskositas, $\mathrm{cp}$

Dari percobaan diketahui bahwa untuk $\mathrm{N}_{\mathrm{Re}}>3000$ adalah turbulen dan $\mathrm{N}_{\mathrm{Re}}<2000$ adalah laminer, diantaranya adalah transisi.

\subsection{Kecepatan Alir Pompa}

Pada pompa lumpur pemboran, kemampuan pompa dibatasi oleh daya maksimumnya, sehingga tekanan dan kecepatan alirnya dapat berubah-ubah seperti yang ditunjukkan dalam persamaan:

$$
H P=\frac{P \cdot Q}{1714}
$$

dimana :

$$
\begin{aligned}
\mathrm{HP}= & \begin{array}{l}
\text { Daya yang diterima pompa dari mesin } \\
\text { penggerak setelah dikalikan efisiensi }
\end{array} \\
& \text { mekanis dan safety, hp } \\
\mathrm{P}= & \text { Tekanan Pemompaan, psi } \\
\mathrm{Q}= & \text { Kecepatan alir, gpm }
\end{aligned}
$$

Bila mempunyai hp maksimum, tekanan pompa maksimum dapat dihitung bila kecepatan alir maksimum telah ditentukan dengan persamaan.

$Q=0.00679 \times S \times N \times\left(2 d_{\text {lin }}^{2}-d_{\text {pist }}^{2}\right) \times e$

dimana :

$\mathrm{S}$ = Panjang stroke, in

$\mathrm{N}=$ Rotasi per menit, $\mathrm{rpm}$ $\mathrm{d}_{\text {pist }}=$ Diameter tangkai piston, in

$\mathrm{d}_{\text {lin }}=$ Diameter liner, in

e $\quad=$ Effisiensi volumetrik

\subsection{Kecepatan Alir Anulus}

Perhitungan kecepatan minimum yang diperlukan untuk mengangkat cutting ke permukaan (cutting velocity) dilakukan di anulus. Kecepatan slip adalah kecepatan minimum dimana cutting dapat mulai terendapkan yang merupakan pengurangan antara kecepatan lumpur dengan kecepatan dari cutting. Vs = VM - VC dimana : Vs $=$ Kecepatan slip, ft/menit $\mathrm{VM}=$ Kecepatan lumpur, $\mathrm{ft} /$ menit $\mathrm{VC}=$ Kecepatan cutting, $\mathrm{ft} /$ menit Dengan memasukkan kondisi yang biasa ditemui dalam operasi pemboran maka didapatkan kecepatan slip sebesar :

$V s=92.5 \sqrt{d c\left(\frac{\rho c}{\rho m}-1\right)}$

Begitu pula rate minimum yang harus dipilih sebesar:

$Q \min =\left\{92.5\left[d c\left(\frac{\rho c}{\rho m}-1\right)\right]^{0.5}+\frac{R O P}{36\left[1-\left(\frac{d p}{d h}\right)^{2}\right] C a}\right\} A$

dimana:

$\mathrm{dc}=$ Diameter cutting terbesar, in

c $\quad=$ Densitas cutting, $\mathrm{lb} / \mathrm{gal}$

$\mathrm{m} \quad=$ Densitas lumpur, lb/gal

Vs $\quad=$ Kecepatan slip, $\mathrm{ft} / \mathrm{min}$

$\mathrm{Q}_{\min }=$ Rate minimum, $\mathrm{ft}^{3} / \mathrm{min}$

$\mathrm{ROP}=$ Kecepatan penembusan, $\mathrm{ft} / \mathrm{jam}$

$\mathrm{Ca}=$ Volume cutting di anulus, $\%$

$\mathrm{dp}=$ Diameter pipa, in

$\mathrm{dh} \quad=$ Diameter lubang, in

$\mathrm{A} \quad=$ Luas anulus, $\mathrm{ft}^{2}$

Menentukan kecepatan maksimum di anulus yang disebut kecepatan kritis.

$V c a=\frac{1.08 P V+1.08\left[9.3(d h-d p) Y b^{2} \rho m\right]^{\frac{1}{2}}}{\rho m(d h-d p)}$

dimana:

$\mathrm{Vca}=$ Kecepatan kritis, $\mathrm{ft} / \mathrm{s}$

$\mathrm{PV}=$ Plastic viscosity, $\mathrm{cp}$

$\mathrm{Yb}=$ Yield point Bingham, $\mathrm{lb} / 100 \mathrm{ft}^{2}$ 


\subsection{Optimasi Hidrolika}

Terdapat beberapa konsep untuk mengusahakan optimalisasi hidrolika pada sistem pemboran diantaranya adalah (Guan et al., 2015).

1) Bit Hydraulic Horse Power (BHHP)

Metoda ini berusaha untuk mengoptimumkan daya (horsepower)

2) Bit Hydaulic Impact (BHI)

Prinsip dasar dari metoda ini, menganggap bahwa semakin besar impak (tumbukan sesaat) yang diterima batuan formasi dari lumpur yang dipancarkan dari bit semakin besar pula efek pembersihannya, sehingga metoda ini berusaha untuk mengoptimumkan impak.

3) Jet Velocity (JV)

Metoda ini berusaha untuk mengoptimumkan laju pompa.

\subsection{Perhitungan Optimasi}

Penentuan ukuran nozzle yang merupakan fungsi dari densitas lumpur, rate optimum dan kehilangan tekanan di bit dijabarkan dalam bentuk persamaan sebagai berikut:

$$
A=\left[\frac{\rho_{m} Q_{o p t}^{2}}{10858 P b}\right]^{0.5}
$$

dimana :

$$
\begin{array}{ll}
\mathrm{m} & =\text { Densitas lumpur, } \mathrm{lbm} / \mathrm{g} \\
\text { Qopt } & =\text { Laju optimum, gal } / \mathrm{min} \\
\mathrm{Pb} & =\text { Pressure loss } \text { pada } \text { bit }, \mathrm{psi}
\end{array}
$$

\section{Metodologi}

Metode pengambilan data diambil secara primer yaitu pengamatan langsung dan diambil pada saat pemboran dan tertera dalam log bore termasuk yaitu mud weight fluida lumpur pemboran diukur di lapangan secara periodik dengan alat mud balance, ukuran lubang bor sesuai dengan diameter bit yang dipakai, untuk ukuran nozzle pada mata bor tercatat, sedangkan kedalaman sumur bor dengan panjang dari pipa yang digunakan untuk pengeboran, data tekanan dan rate pemompaan dicatat dari manometer dan barometer pada pompa lumpur yang digunakan tercatat dalam log bore.
Pada penelitian ini, Sumur yang di evaluasi adalah sumur "SH", Lapangan "U" metoda optimasinya adalah menggunaan Jet Velocity (JV). Variabel terikatnya metode ini adalah, rasio optimasi, daya penetrasi, dan laju aliran, dan ukuran nozzle. Data yang diperlukan sebagai variabel bebas adalah kedalaman penetrasi, tekanan pompa, dan densitas lumpur pemboran. Langkah-langkah untuk menentukan optimasi dalam konsep JV adalah sebagai berikut :

Langkah - langkah untuk menentukan optimasi adalah sebagai berikut :

\section{a. Kondisi Tekanan Maksimum}

1. Hitung kehilangan tekanan di bit.

2. Hitung rate optimum

3. Perhatikan apakah $Q_{\text {opt }}$ lebih kecil dari rate maksimum $\left(\mathrm{Q}_{\max }\right)$. Jika tidak terpenuhi maka, $\mathrm{Q}_{\text {opt }}=\mathrm{Q}_{\max }$

4. Perhatikan apakah $\mathrm{Q}_{\text {opt }}$ tersebut lebih besar dari rate minimum $\left(\mathrm{Q}_{\min }\right)$. Jika tidak terpenuhi, maka $\mathrm{Q}_{\mathrm{opt}}=\mathrm{Q}_{\mathrm{min}}$

5. Hitung daya yang diperlukan di permukaan (HPs)

6. Perhatikan apakah daya yang diperlukan di permukaan (HPs) tersebut tidak lebih besar dari daya maksimum pompa (HPm). Jika tidak terpenuhi, bisa dicoba dengan kondisi daya maksimum.

7. Hitung luas nozzle total yang optimum .

\section{b. Kondisi Daya Maksimum}

1. Hitung kehilangan tekanan di bit.

2. Hitung rate optimum $\left(\mathrm{Q}_{\mathrm{opt}}\right)$ dengan persamaan : $\mathrm{Q}_{\mathrm{opt}}=\mathrm{Q}_{\text {min }}$

3. Hitung tekanan yang diperlukan di permukaan (Ps).

4. Perhatikan apakah Ps lebih kecil dari tekanan maksimum pompa (Pm). Jika tidak terpenuhi, bisa dicoba dengan kondisi pertengahan.

5. Hitung luas nozzle total yang optimum.

\section{c. Kondisi Pertengahan}

1. Hitung rate optimum $\left(\mathrm{Q}_{\mathrm{opt}}\right)$.

2. Hitung kehilangan tekanan di bit.

3. Hitung luas nozzle total yang optimum.

Diagram alir perhitungan optimasi pengeboran dengan metode BHHP ini dapat dilihat pada Gambar 1. 


\section{OPTIMASI HIDROLIKA SUMUR "SH" LAPANGAN "U” KALIMANTAN TIMUR DENGAN METODE BIT HYDROULIC HORSE POWER}

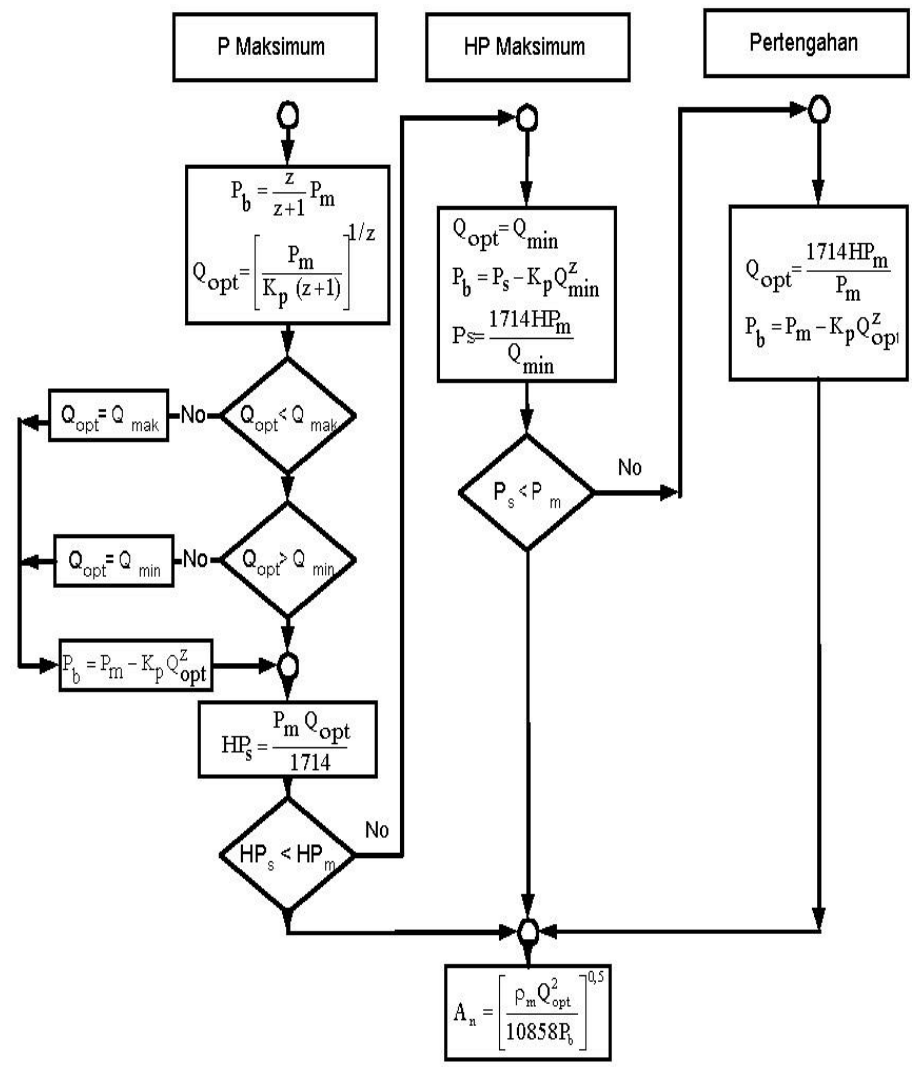

Gambar 1. Diagram Alir Penentuan Parameter Hidraulik Proses Pemboran Menggunakan Metode BHHP

\section{Hasil dan Pembahasan}

Optimasi sistem hidraulika pengeboran menggunakan metode Bit Hydraulic Horse Power (BHHP) telah membantu operator pengeboran dalam hal mengevaluasi performa nozzle pada mata bor (bit) serta mengevaluasi apakah sistem hidraulika pengeboran berjalan dengan baik atau tidak.

Gambar 2 menunjukkan perbedaan kurva laju aliran fluida pengeboran yang dibutuhkan pada sistem hidraulika pengeboran terhadap kedalaman penetrasi mata bor. Dari kurva tersebut terlihat bahwa laju aliran fluida pengeboran dengan menggunakan data aktual adalah $289 \mathrm{gal} / \mathrm{min}$ pada kedalaman penetrasi $9915 \mathrm{ft}$ dan laju aliran tertinggi adalah $467 \mathrm{gal} / \mathrm{min}$ pada kedalaman penetrasi $7276 \mathrm{ft}$. Adapun menurut perhitungan optimasi menggunakan $B H H P$, laju aliran terendah adalah 196,19 gal/min untuk kedalaman penetrasi $10220 \mathrm{ft}$ dan yang tertinggi berada pada nilai 308,66 gal/min pada kedalaman 5864 ft. Apabila data actual laju aliran fluida pengeboran semakin mendekati nilai laju aliran fluida dari data $B H H P$, maka dapat dikatakan nilai laju aliran fluida tersebut mendekati nilai yang diharapkan. Besarnya penyimpangan antara data aktual dengan data metode $B H H P$ dapat diukur melalui rasio antara laju aliran menggunakan data aktual terhadap laju aliran menggunakan metode $B H H P$ $\left(\left(\mathrm{Q}_{\mathrm{opt}} / \mathrm{Q}_{\text {aktual }}\right)\right.$ x $\left.100 \%\right)$ yang ditunjukkan pada gambar 3. Dari kurva rasio tersebut, rata-rata rasio yang dicapai adalah $65,4 \%$. artinya performa sistem hidraulika pengeboran masih dapat dikatakan baik, tetapi perlu di beberapa titik perlu diturunkan lagi laju aliran fluidanya karena nilai rasionya masih kurang dari $65 \%$ yaitu pada kedalaman penetrasi $5864 \mathrm{ft}, 9151 \mathrm{ft}, 9585 \mathrm{ft}$ dan $9915 \mathrm{ft}$. titik kedalaman penetrasi yang paling mendekati nilai $B H H P$ adalah pada titik $8918 \mathrm{ft}$ dengan rasio laju aliran antara data aktual dan data BHI (Bottom Hole Impact) adalah 95,64\%. 


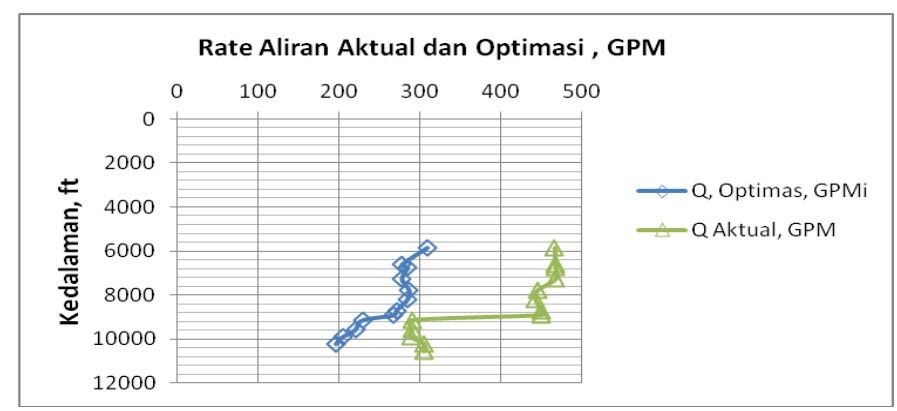

Gambar 2. Laju Aliran Lumpur Aktual dan Optimum (Hp) versus Kedalaman Lubang Bor Sumur, ft.

Gambar 3 menunjukkan kurva laju aliran fluida pengeboran terhadap kedalaman penetrasi, cara tebaik untuk mengoptimasi laju aliran pada titik-titik kurva tersebut adalah dengan cara menyesuaikan ukuran diameter atau luas lubang nozzle dari mata bor (bit) dengan ukuran yang diharapkan dalam metode BHHP dengan menggunakan persamaan (7) di atas. Tabel 1 di bawah menunjukkan beberapa perbandingan parameter-parameter fisika untuk sistem hidraulika pengeboran antara data actual dengan data metode $B H H P$ serta nilai luasan lubang nozzle dari mata bor berdasarkan perhitungan metode
BHHP. Dari data pada tabel 1 tersebut, untuk kedalaman penetrasi pengeboran $6628 \mathrm{ft}, 6753 \mathrm{ft}$, $7276 \mathrm{ft}$ dan $8708 \mathrm{ft}, 8918 \mathrm{ft}$ dapat disesuaikan kembali ukuran luasan lubang nozzle mata bor secara berturut-turut menjadi $0,2089 \mathrm{in}^{2}, 0,2155 \mathrm{in}^{2}, 0,2101$ in $^{2}$ 0,2059 $\mathrm{in}^{2}$, dan 0,2033 $\mathrm{in}^{2}$. Adapun daya aktual ada yang kebesaran yaitu pada kedalaman $5864 \mathrm{ft}$ sampai dengan $8981 \mathrm{ft}$ dan kedalaman $10220 \mathrm{ft}$, $10564 \mathrm{ft}$ ada juga yang lebih kecil kedalaman $9151 \mathrm{ft}$, $9585 \mathrm{ft}$ dan $9915 \mathrm{ft}$, terlihat pada gambar 4 .

Tabel 1. Parameter Fisika Pada Sistem Hidraulika Pengeboran dengan Menggunakan Data Aktual dan Data Metode $B H H P$

\begin{tabular}{|r|c|c|c|c|c|c|c|c|c|c|c|}
\hline No & $\begin{array}{c}\text { Kedalaman } \\
\text { (ft) }\end{array}$ & $\begin{array}{c}\text { Mud Weight } \\
\text { (Ib/gal) }\end{array}$ & $\begin{array}{l}\text { Ppompa } \\
\text { (Psi) }\end{array}$ & $\begin{array}{c}\text { Q Aktual } \\
\text { (GPM) }\end{array}$ & $\begin{array}{c}\text { Qopt BHHP } \\
\text { (GPM) }\end{array}$ & $\begin{array}{c}\text { Pbit aktual } \\
\text { (Psi) }\end{array}$ & $\begin{array}{c}\text { Pbit BHHP } \\
\text { (Psi) }\end{array}$ & $\begin{array}{c}\text { Daya aktual } \\
\text { (hp) }\end{array}$ & $\begin{array}{c}\text { Daya optimum } \\
\text { (hp) }\end{array}$ & $\begin{array}{c}\text { Ratio Rate } \\
\text { (\%) }\end{array}$ & $\begin{array}{c}\text { Nozzle BHHP } \\
\text { (In })^{\mathbf{}}\end{array}$ \\
\hline 1 & 5864 & 9.96 & 1900 & 466 & 308.66 & 1759.22 & 1617 & 516.57 & 457.59 & 66.24 & 0.2325 \\
\hline 2 & 6628 & 9.96 & 2300 & 467 & 277.33 & 1863.09 & 1617 & 626.66 & 411.14 & 59.39 & 0.2089 \\
\hline 3 & 6753 & 10.08 & 2200 & 467 & 284.47 & 1547.82 & 1617 & 599.42 & 421.72 & 60.91 & 0.2155 \\
\hline 4 & 7276 & 10.08 & 2300 & 467 & 277.33 & 1685.79 & 1617 & 626.66 & 411.14 & 59.39 & 0.2101 \\
\hline 5 & 7796 & 10.18 & 2000 & 445 & 286.24 & 1922.64 & 1617 & 519.25 & 424.35 & 64.32 & 0.2179 \\
\hline 6 & 8206 & 10.16 & 2000 & 442 & 284.31 & 1818.02 & 1617 & 515.75 & 421.49 & 64.32 & 0.2163 \\
\hline 7 & 8708 & 10.16 & 2250 & 450 & 270.61 & 2084.08 & 1617 & 590.72 & 401.18 & 60.14 & 0.2059 \\
\hline 8 & 8918 & 10.16 & 2300 & 450 & 267.24 & 2193.97 & 1617 & 603.85 & 396.18 & 59.39 & 0.2033 \\
\hline 9 & 9151 & 10.16 & 1400 & 290 & 228.71 & 1499.92 & 1617 & 236.87 & 339.06 & 78.86 & 0.1740 \\
\hline 10 & 9585 & 10.49 & 1500 & 290 & 219.87 & 1684.55 & 1617 & 253.79 & 325.95 & 75.82 & 0.1700 \\
\hline 11 & 9915 & 12.33 & 1700 & 289 & 203.98 & 1429.82 & 1617 & 286.64 & 302.41 & 70.58 & 0.1709 \\
\hline 12 & 10220 & 12.66 & 2000 & 305 & 196.19 & 2003.92 & 1617 & 355.89 & 290.84 & 64.32 & 0.1666 \\
\hline 13 & 10564 & 13.83 & 1850 & 305 & 205.12 & 855.52 & 1617 & 329.20 & 304.09 & 67.25 & 0.1820 \\
\hline
\end{tabular}

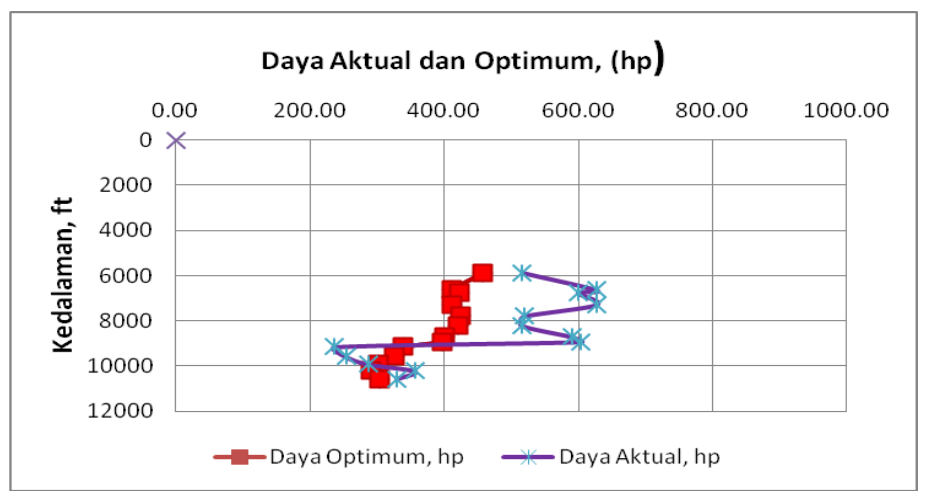

Gambar 3. Grafik Rasio Laju Aliran Lumpur Bor versus Kedalaman Lobang Bor Sumur, ft. 


\section{OPTIMASI HIDROLIKA SUMUR "SH" LAPANGAN "U" KALIMANTAN TIMUR DENGAN METODE BIT HYDROULIC HORSE POWER}

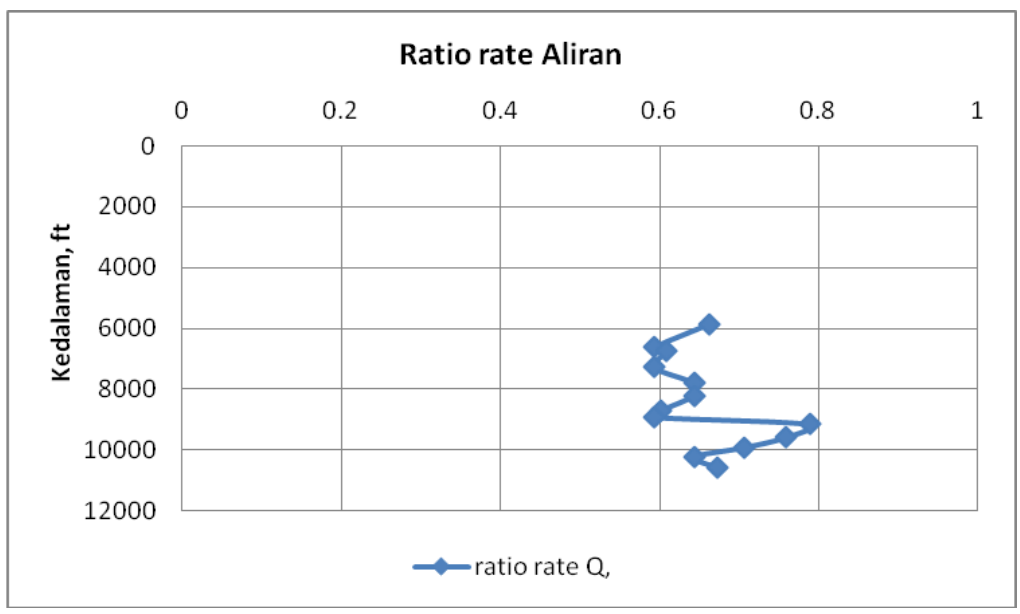

Gambar 4. Grafik Daya Aktual dan Optimum (Hp) Versus Kedalaman Lubang Bor Sumur, ft.

\section{Kesimpulan}

Hasil evaluasi dan optimasi Bit Hydrolic Horse Power (BHHP) disimpulkan bahwa pada trayek semua kedalaman perlu diturunkan laju aliran lumpur pemborannya rata-rata sampai $65,4 \%$ dengan cara menyesuaikan ukuran lubang nozzle sesuai yang disarankan dari perhitungan metode BHHP yaitu secara berturut-turut menjadi $0,23 \mathrm{in}^{2}$, $0,20 \mathrm{in}^{2}, 0,21 \mathrm{in}^{2}, 0,21 \mathrm{in}^{2}, 0,21 \mathrm{in}^{2}, 0,21 \mathrm{in}^{2}, 0,20$ $\mathrm{in}^{2}, 0,20 \mathrm{in}^{2}, 0,17 \mathrm{in}^{2}, 017 \mathrm{in}^{2}, 0,17 \mathrm{in}^{2}, 0,16 \mathrm{in}^{2}$ dan 0,18 in $^{2}$. Selain itu, Konsep BHHP menggunakan daya yang optimum dan dari laju aliran fluida pemboran dengan nilai optimum sehingga pembersihan cutting dapat berlangsung dengan baik.

\section{Daftar Pustaka}

Al-Kayiem, H. H., Zaki, N. M., Asyraf, M. Z., \& Elfeel, M. E. 2010. Simulation of the Cuttings Cleaning During the Drilling Operation. American Journal of Applied Sciences, 7(6), 800-806.

Coussot, P., Bertrand, F., \& Herzhaft, B. 2004. Rheological Behavior of Drilling Muds, Characterization Using MRI Visualization. Oil \& Gas Science and Technology Rev. IFP, 59(1), 23-29.

Guan, Z., Liu, Y., Li, Q., Xu, Y., \& Pang, H. 2015. Drilling Hydraulic Parameters Design Method under the Limited Circulating System
Bearing Capacity Condition. Journal of Applied Science and Engineering, 18(3), 303308. http://doi.org/10.6180/jase.2015.18.3.11

Haryono, S., dan Widyawidura, W. 2016. Optimasi Hidrolika Sumur $X$ Lapangan Bunyu Kalimantan Timur dengan Metode Bit Hydroulic Impact. Jurnal Mekanika dan Sistem Termal, Vol. 1(3), Desember 2016: 87-91. Wittig, V., Bracke, R., \& Hyun-ick, Y. (2015). Hydraulic DTH Fluid / Mud Hammers with Recirculation Capabilities to Improve ROP and Hole Cleaning For Deep , Hard Rock Geothermal Drilling. In Proceedings World Geothermal Congress 2015 (pp. 1925).

Kelessidis, V. C., Dalamarinis, P., \& Maglione, R. 2011. Experimental Study And Predictions Of Pressure Losses Of Fl Uids Modeled As Herschel - Bulkley In Concentric And Eccentric Annuli In Laminar, Transitional And Turbulent Fl Ows. Journal of Petroleum Science and Engineering, 77, 305-312. http://doi.org/10.1016/j.petrol.2011.04.004

Miguez, L., \& Janeiro, R. De. 2011. Hydraulic Study of Drilling Fluid Flow in Circular and Annular Tubes. Brazilian Journal of Petroleum and Gas, 5(4), 239-253. http://doi.org/10.5419/bjpg2011-0023 
Noah, A. Z. 2013. Optimizing Drilling Fluid Properties and Flow Rates for Effective Hole Cleaning at High-Angle and Horizontal Wells. Journal of Applied Sciences Research, 9(1), 705-718.

Paiaman, A. M., Al-askari, M. K. G., Salmani, B., \& Masihi, M. 2006. Effect of Drilling Fluid Properties on Rate of Penetration. NAFTA, 60(3), 129-134. R. Monicard (1982) Drilling Mud and Slurry Rheology ISBN 2-7108-04204 France, 1982.
Rubiandini. R.S., 2010. Hydrolika Lumpur Pemboran. Handbook Drilling Engineering. ITB Bandung 452-731.

Saasen, A., \& Løklingholm, G. 2002. The Effect of Drilling Fluid Rheological Properties on Hole Cleaning. In IADC / SPE 74558 Drilling Conference (pp. 1-5). Texas. Samsuri, A., \& Hamzah, A. (2011). Water based mud lifting capacity improvement by multiwall carbon nanotubes additive. Journal of Petroleum and Gas Engineering, 2(5), 99-107. 